\title{
Clinical Study Activity Relationship Type
}

National Cancer Institute

\section{Source}

National Cancer Institute. Clinical Study Activity Relationship Type. NCI Thesaurus. Code C70970.

An attribute that defines the meaning and purpose of a clinical study activity relationship instance. 